\title{
La poesía de Pere Rovira: una panorámica
}

Joan Calsina

Pere Rovira es, sin duda alguna, una de las voces más singulares, valiosas y trascendentes del panorama literario catalán actual. Por encima de todo, es un escritor que cuenta con unas insólitas aptitudes literarias, pero que disfruta, también, de una vastísima preparación intelectual. Estas inestimables cualidades le han permitido conformar una obra diversa y heterogenia: a lo largo de su carrera como escritor - y en especial, durante los últimos quince años - ha conreado géneros tan diversos como la novela, el ensayo, el cuento, el dietario o la traducción; y, además, lo ha hecho siempre con gran acierto y con un rigor artístico muy elevado. Sin embargo, de entre todas estas vertientes creativas, es sin duda su actividad poética lo que — sin desmerecer el resto de su obra— más lo ha caracterizado y definido como creador. La poesía es, en efecto, el género en que Rovira ha conseguido unos niveles más altos de calidad literaria, de expresividad, de dominio lingüístico, de seguridad técnica y formal. Tanto es así que, ya a día de hoy, lo podemos considerar como uno de los poetas en activo más importantes — si no el más importante- de la literatura catalana, y, al mismo tiempo, como el principal continuador en esta lengua de dos escuelas poéticas de larga tradición como son el realismo moral y el simbolismo.

No obstante, y a pesar de la importancia de su poesía, el conjunto de su obra en verso es relativamente breve. El corpus poético del autor está compuesto de cinco libros publicados entre 1981 y 2011: Distàncies $(1981)^{1}$, Cartes marcades $(1988)^{2}$, La vida en

1. Pere Rovira, Distàncies, Eliseu Climent, València, 1981.

2. Pere Rovira, Cartes marcades, Península-Edicions 62, Barcelona, 1988. 
plural (1996) 3$)^{3}$ La mar de dins $(2003)^{4}$ y Contra la mort (2011) $)^{5}$. Esta relativa brevedad es debida a su propia concepción del género; a pesar de la evidente transcendencia que ha tenido la poesía en el desarrollo de su vida personal, el cultivo de este tipo de escritura nunca se ha concretado en un trabajo diario, constante, absolutamente regular, sino que ha ido siempre ligado a la coyuntura de cada momento y a la necesidad de una especial predisposición que, al fin y al cabo, ha resultado ser de una frecuencia más bien variable. Sea como fuere, el volumen total de su corpus poético resulta suficiente para constatar la formación de una obra de una gran solidez, perfectamente coherente y de una calidad literaria incuestionable; $y$ tenemos que añadir, también, de una nada desdeñable diversidad, cosa que le otorga un sentido evolutivo y una riqueza más que remarcable des del punto de vista técnico, temático y estilístico.

En primer lugar, es preciso de afirmar que la poesía de Rovira se caracteriza por una evidente tendencia hacia al realismo. Sus versos no transitan por la senda de lo estrictamente metafísico o de un cierto hermetismo, no se trata de una poesía oscura y marcadamente simbólica, aunque en determinados momentos tampoco excluya esas posibilidades. En verdad, las composiciones del autor catalán parten casi siempre de situaciones verosímiles, plausibles, situaciones que presentan una evidente conexión con la realidad y con la cotidianidad. Podemos afirmar, incluso, que se llega a establecer una clara vinculación entre la obra en verso y la propia intimidad del poeta, entre los pretextos narrativos utilizados y su vida personal; las vivencias del día a día tienen un peso muy considerable en el aspecto temático de las composiciones. Como es lógico, sus versos también contienen una parte muy importante de ficción, de figuración e inventiva, pero resulta manifiesto, en la misma medida, que las relaciones con su cotidianidad son estrechas, complejas, y, a veces, incluso bastante difíciles de discernir. Esto provoca que el sujeto poético predominante del conjunto de su obra suela ser, también, alguien próximo a su experiencia, a su personalidad y a su carácter, o, por lo menos coherente con su personalidad y su carácter. Por lo tanto, sus creaciones acostumbran a vincularse a las vivencias individuales y a la cotidianidad, a lo que él mismo ha definido en otros contextos como "vida viscuda".

Ahora bien, las ideas hasta ahora expresadas no han de inducirnos a pensar que la poesía de Pere Rovira consista en un mero registro de experiencias cotidianas más bien fútiles o anodinas. Nada más lejos de su intención que presentar un catálogo biográfico o una lista de curiosidades costumbristas, en absoluto. De la misma manera que tenemos que admitir la conexión con la realidad, es importante precisar que sus textos también incluyen una multiplicidad de capas de lectura y un grado de abstracción que, a veces,

3. Pere Rovira, La vida en plural, Columna Edicions, Barcelona, 1996.

4. Pere Rovira, La mar de dins, Proa, Barcelona, 2003.

5. Pere Rovira, Contra la mort, Proa, Barcelona, 2011. En esta enumeración nos limitamos a mencionar tan solo los poemarios originales. Por lo tanto, excluimos de esta lista las antologías, plaquettes, folletos y otras obras publicadas que se podrían considerar secundarias o redundantes en el conjunto de su poesía.

6. Pere Rovira, Les roses de Ronsard, Proa, Barcelona, 2009, pág. 19. 
resulta muy elevado; y, asimismo, también una profunda voluntad de reflexión y de trascendencia. Su obra, es cierto, nace a menudo a partir de pretextos próximos a la realidad, de experiencias humanas de tipo vivencial; pero, al mismo tiempo, Rovira nunca se conforma con una insubstancial enumeración de los hechos que han pasado, que están pasando o que pueden ocurrir. Sus textos pueden partir de anécdotas más o menos interesantes, pero la voluntad final del poeta es ofrecer una reflexión que ultrapase las excusas narrativas. En este sentido, es pertinente hacer referencia a un sugerente principio de Salvador Espriu que Rovira casi ha convertido en una divisa: tal como él ha defendido en diversas ocasiones, un poema ha de ser por encima de todo "clar i difícil", por más que ello pueda parecer una contradicción; los versos pueden tener, en un principio, una apariencia más bien llana, pueden parecer sencillos e incluso diáfanos, pero por debajo de esa apariencia de simplicidad deben ofrecer distintas capas de comprensión, múltiples interpretaciones, tienen que procurar superar en gran medida el pretexto narrativo y lograr una concepción más elevada, más profunda, de la que aparentan de buen principio.

En consecuencia, Rovira no es un autor meramente autobiográfico, sino que procura construir un entramado reflexivo a partir de las observaciones y actitudes que las situaciones cotidianas puedan suscitar; es decir, su intención es dotar al poema de una articulación razonada y de una dimensión moral, de una evaluación lo más precisa posible del elevado coste que comportan las experiencias vividas. De ello se explica que, a menudo, se haya enmarcado el conjunto de su obra dentro de la escuela de poetas de la experiencia o dentro de la corriente del realismo moral, o que incluso, en algunas ocasiones, se le

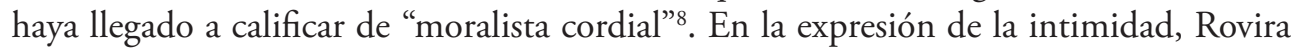
procura transmitir una experiencia humana que, ciertamente, resulte en todo momento cordial y honesta, que sea contraria a cualquier tipo de tópico o de autoengaño. Por otro lado, su estilo se caracteriza por evitar las afectaciones innecesarias y los sentimentalismos, cosa que no significa, por supuesto, que no pueda hablar de sentimientos o de emociones, pero sí que rehúya las actitudes indecorosas o histriónicas. Tampoco los efectismos o el lenguaje en exceso alambicado suelen ser habituales en su poesía, a pesar de la importancia que concede al aspecto formal y al dominio creciente de la técnica a lo largo de su producción. Por el contrario, su forma de expresión presenta una relativa sobriedad; su escritura es nítida, fluida, comprensible. Es una escritura exacta, sin elementos superfluos, pero que al mismo tiempo plantea mensajes que no son unívocos ni simplistas, sino múltiples, complejos, profundos. A veces, el tono puede parecer bastante llano, en otras ocasiones rotundo e incluso cruento, pero, en cualquier caso, nada de eso lo induce a abandonar su principio compositivo, su intención primera, la necesidad de mantener la máxima sinceridad moral.

7. Hay diversos casos. Véase por ejemplo Pere Rovira "Clar i difícil”, Pere Rovira, Diari sense dies, Proa, Barcelona, 2005, pág. 163 y 164.

8. Joan Margarit, "Pere Rovira: navegant per un mar interior", Caràcters, 24 (2003), pág. 26 y 27. 
Son estas unas cuestiones que Francisco Díaz de Castro ha descrito con especial acierto:

Sin concesiones a la galería y sin remilgos esteticistas, este poeta nada apresurado elabora su obra mirando de frente la realidad de las cosas y las relaciones humanas y con una inapelable sensatez que el sentimiento enriquece y la ironía multiplica en facetas de rigurosa ética.

[...] Pere Rovira une a una aguda conciencia lingüística la decidida voluntad de no pasar por alto las exigencias y las implicaciones — miserias y grandezas - del breve tramo de la vida, y ello des de los presupuestos de una poesía de la experiencia que alcanza siempre a extraer su lección moral de todo cuanto observa o reconstruye. $\mathrm{Al}$ margen de ciertas poéticas de vacíos hermetismos y de "Cultureta de ruïnes", en su caso no hay duda de que sabe por qué escribe poesía, y de qué tipo de poesía le importa $[. . .]^{9}$

Y además de lo dicho hasta ahora, es necesario destacar aún otro elemento fundamental de la poesía de Pere Rovira que ya hemos apuntado en el principio de este artículo: el equilibrio que demuestra entre la solidez de su voz, por una parte, y la riqueza y la diversidad de procedimientos compositivos, por otra. A pesar del dicho carácter tendiente a la brevedad de su obra, el autor demuestra una gran amplitud de recursos, de técnicas y procedimientos, tanto en las vertientes técnicas, narrativas, como también temáticas y conceptuales. Rovira no es en absoluto un poeta que acostumbre a basarse en una determinada forma tipificada y la mantenga invariable a lo largo de todas sus colecciones de poesía, al contrario; demuestra una gran capacidad de cambio, de evolución e incluso de reinvención, que comporta, en definitiva, que cada uno de sus libros sean muy diversos entre sí. Sus poemas pueden dividirse en tipologías tan diversas como el monólogo dramático, el correlato objetivo o la elegía, o incluso algunos subgéneros de carácter más personal como el correlato naturalista o, por supuesto, su característica elegía en futuro. En el aspecto formal, sus poemarios basculan des de unos inicios tendientes a una cierta libertad métrica —en su primer libro, Distàncies-, hasta una elevada exigencia que resulta cada vez más acentuada - especialmente, en Contra la mort. Sin embargo, y no obstante esa riqueza, Rovira es capaz de mantener un estilo que resulta siempre coherente, compacto; es capaz de conservar una voz que resulta sólida y siempre reconocible. Seguramente, esa es una de las cualidades de su obra que es más importante resaltar, a saber, el equilibrio entre una personalidad artística definida y la capacidad de cambio y adaptación a nuevos contextos. De hecho, tal como señala el propio Rovira, sus libros son ciertamente distintos entre sí, y, no obstante, pueden llegar a parecer capítulos de una misma unidad: juntos, sus poemarios son algo así como "capítols d'un llibre nou" ${ }^{10}$.

9. Francisco Díaz de Castro, "Palabras con sentido", Francisco Díaz de Castro, Vidas pensadas. Poetas de fin de siglo, Renacimiento, Sevilla, 2002, pág. 50.

10. Pere Rovira, Poesia 1979-2004, Proa, Barcelona, 2006, pág. 12. 
Como es lógico, las cuestiones mencionadas hasta ahora también se reflejan en gran medida en los aspectos temáticos de su obra. Es cierto que a lo largo de toda su producción la diversidad temática es muy considerable; las cuestiones que plantea el autor, como es natural, son diversas, y sus intereses, por supuesto, no son inamovibles, sino que van cambiando con los años. Así, si en Distàncies o Cartes marcades la singularidad del yo poético resultaba fundamental, en La vida en plural tomará importancia el aspecto social, las relaciones familiares y de amistad; en La mar de dins, en cambio, la muerte será sin duda el gran tema que dominará la colección, mientras que a Contra la mort la reivindicación de la vida, del placer sensual y de la experiencia amorosa serán la clave del poemario. Aun así, es indudable que existen una serie de cuestiones que resultan más recurrentes que otras, más habituales, y que, al fin y al cabo, se convierten en aspectos transversales de su producción; unas cuestiones que, en verdad, están estrechamente vinculadas a las características básicas de su poesía a las cuales nos hemos referido hace un instante. Después de todo, el personaje principal que domina los versos de Rovira es, en efecto, alguien próximo al propio autor, a su manera de ser, a su carácter; con una vida cotidiana que, hasta cierto punto, es similar a la suya. Como ya se ha dicho, es alguien que observa su entorno y lo evalúa, pero que también analiza su propia interioridad, y que siempre la pone en relación con su propia situación en el mundo. En otras palabras, el sujeto poético tiende a medir las distancias — físicas, espirituales, morales e ideológicas - que le separen de la gente que le rodea, normalmente en el ámbito reducido de la intimidad, a veces en un ámbito más amplio, público, colectivo. ${ }^{11} \mathrm{Y}$ es a partir de esa mirada incisiva hacia uno mismo y hacia el exterior de donde se derivan, precisamente, los que son, muy probablemente, los dos grandes aspectos temáticos que, en última instancia, traviesan el conjunto de su poesía. Nos referimos, en primer lugar, a la reflexión sobre los vínculos afectivos, es decir, la reflexión sobre las relaciones entre las personas y los sentimientos compartidos que las unen; en segundo lugar, y emparentado muy de cerca con el primer aspecto, la manera como el paso de los años, el transcurrir del tiempo y de la vida, condiciona los vínculos que acabamos de mencionar.

Ciertamente, las relaciones humanas entendidas en un sentido amplio son, muy probablemente, el aspecto fundamental de la poesía de Pere Rovira. A lo largo de su obra podemos encontrar referencias constantes a los afectos íntimos: al amor conyugal, al amor paterno o al valor que otorga a la amistad. En ocasiones, también podemos encontrar unas relaciones humanas entendidas des del punto de vista de la comunidad, del colectivo, como el conjunto de una sociedad; en alguno de sus libros es posible identificar, incluso, ciertas aproximaciones a la poesía social, si bien de carácter más bien puntual. Pero tanto en un caso como en el otro, ya sea en el ámbito privado o en la esfera pública, Rovira plantea unas relaciones humanas que no son en absoluto inamovibles, al contrario, están siempre en movimiento: son unos afectos planteados como

11. Unas "distàncies" que quedan reflejadas en el título de su primer libro y cuya significación simbólica ha descrito con acierto Xavier Macià en su artículo "Lart de mesurar distàncies. Poesia completa de Pere Rovira”, Reduccions, 91, 2008, pág. 99-106. 
una evolución que se desarrolla en el tiempo, y, por lo tanto, hay siempre la consciencia de unas relaciones que se han transformado, que se están transformando o que se transformaran en el futuro. La consciencia del paso del tiempo, del cambio permanente y del envejecimiento son cuestiones que de manera más o menos explícita tienen una notable presencia en su poesía, y que muy a menudo lo conducen a tomar posturas de tipo reflexivo y de voluntad de comprensión sobre su naturaleza. El sujeto poético se plantea las dificultades que implican estas relaciones con la intimidad y con la comunidad, con la propia personalidad, con las personas más próximas y también las que no lo son tanto. Se plantea, en definitiva, las dificultades derivadas de la intemperie moral a que las personas nos encontramos sometidos en nuestra cotidianidad. Por lo tanto, no se trata tan solo de una simple observación de estas relaciones — que también lo es- sino sobre todo de un intento de comprenderlas, de profundizar, de reflexionar y avaluar el coste que los afectos compartidos producen en la vida del individuo.

En una reciente entrevista, Pere Rovira afirmaba que el impulso literario sirve, entre otras cosas, para vencer a la muerte. ${ }^{12}$ Una afirmación sin duda contundente. No obstante, no deja de ser verdad que la expresión artística ha sido des de siempre una herramienta — más bien una auténtica arma, quizá de las más potentes—, para perseverar en la reivindicación y en la defensa de la vida. El arte es, seguramente, una de esas pocas cosas que nos permite afrontar la inevitable derrota con que la muerte, siempre poseedora de las mejores cartas, amenaza de alcanzarnos algún día. Y, en ese sentido, no hay duda que los versos de Pere Rovira nos ofrecen un magnífico refugio, una protección, un espacio seguro frente los embates inclementes del sufrimiento. La poesía de Pere Rovira nos ofrece un reducto de bienestar siempre dominado por el vitalismo, por la reflexión y por los afectos íntimos. Unos afectos que, a menudo, pueden ayudarnos a recordar un poco mejor lo que somos y hacia dónde vamos. Y también a ser, quizá, mejores personas.

12. Véase el inicio de la entrevista "Pere Rovira. 70 anys. Una crónica”, disponible en línea: [https://www. youtube.com/watch?v=umsydPGKHRo]. 